\title{
Phenotypic methods for speciating clinical Aeromonas isolates
}

\author{
M H Wilcox, A M Cook, K J Thickett, A Eley, R C Spencer
}

\begin{abstract}
Aims: To establish the suitability of currently available phenotypic methods for speciation of clinical Aeromonas isolates in diagnostic microbiology laboratories.

Methods: Using 62 Aeromonas spp, three schemes based on biochemical reactions were compared: a series of conventional tests; a system based on the suicide phenomenon, comprising two tubes in total; and a commercially available test, API 20 $\mathrm{NE}$, augmented with a plate assay for $\beta$ haemolysin production. The whole cell and outer membrane protein (OMP) profiles of strains were examined by sodium dodecyl sulphate polyacrylamide gel electrophoresis (SDS PAGE), according to the results of the above schemes, to determine the intra-species homogeneity.

Results: Ninety per cent of strains were identified satisfactorily according to conventional criteria. For these strains, agreement was obtained using the suicide phenomenon and API schemes in $93 \%$ and $88 \%$ of cases, respectively. The three schemes concurred for $82 \%$ of strains. Whole cell protein profiles were unsuitable for comparing strains within a species. However, OMP patterns were similar for $89 \%$ of $A$ caviae and $63 \%$ of $A$ hydrophila.

Conclusion: Phenospeciation of clinical Aeromonas isolates by the scheme based on the suicide phenomenon is simple to perform and accurate, and suitable for use in the diagnostic laboratory. OMP profiles are potentially useful for confirming the identity of $A$ caviae and most $A$ hydrophila, but not $A$ sobria.
\end{abstract}

(F Clin Pathol 1992;45:1079-1083)

Members of the genus Aeromonas were first recognised 100 years ago. Since then the taxonomy of these bacteria has undergone constant modification, resulting in considerable confusion. ${ }^{1-3}$ Recently, in an effort to clarify the situation, DNA-DNA hybridisation techniques have been used. (Farmer JJ, et al. Abstract presented at the First International Workshop on Aeromonas and Plasiomonas, 1986). ${ }^{4}$ However, the results of such work have, in some instances, complicated the taxonomy of Aeromonas spp still further. Currently the genus can be split into 13 DNA hybridisation groups of genospecies. By com- parison, using biochemical tests and other phenotypic markers at least seven phenospecies can be differentiated. ${ }^{35}$

A classification based on genospeciation therefore presents the problem that a number of genospecies can only be identified using DNA hybridisation techniques, which are not available in most diagnostic laboratories. By comparison, phenotyping is much simpler, usually requiring standard biochemical tests. $^{5-7}$ Kuijper et al have also described a protein phenotyping method for aeromonads which compared outer membrane proteins (OMPs). ${ }^{8}$ They found that this method could be used to identify strains of $A$ hydrophila, $A$ caviae, and $A$ sobria ( $A$ veronii biovar sobria). However, the protein traces obtained had many bands and were therefore difficult to analyse, with strains of $A$ hydrophila and $A$ sobria showing considerable variation within species.

Evidence is accumulating to suggest that particular Aeromonas spp cause infection in certain clinical situations. For example, $A$ caviae seems to be associated with gastroenteritis in infants. ${ }^{9-11}$ Simple and reliable speciation techniques are required if diagnostic microbiology laboratories are to be able to identify Aeromonas isolates, and so provide further information on their prevalence and pathogenicity. In this study three biochemical phenotypic methods for the speciation of clinical Aeromonas isolates were compared: conventional biochemical typing ${ }^{67}$; speciation according to the suicide phenomenon ${ }^{12}$; and a commercial method (API 20NE strips, API, Basingstoke) in conjunction with a simple haemolysin plate assay. The results of these biochemical methods were correlated with both whole cell and OMP profiles.

\section{Methods}

Sixty two Aeromonas spp were studied, comprising 27 and 29 faecal isolates from adults and children, respectively, who had been investigated for gastroenteritis in Sheffield. Six reference strains, including three kindly supplied by T Donovan (PHLS Laboratory, Ashford, Kent), and American Type Culture Collection strains ATCC 15468, 7966, and 43979 ( $A$ caviae, $A$ hydrophila, and $A$ sobria, respectively) were used. All strains were oxidase positive, fermentative Gram negative bacilli, resistant to both low (10 $\mu \mathrm{g}$ disc) and high $(150 \mu \mathrm{g}$ disc) concentrations of the vibriostatic agent 0129 . 
CONVENTIONAL BIOCHEMICAL METHODS

Specification was achieved according to the criteria of Popoff and Veron, ${ }^{6}$ modified by Janda et al. ${ }^{7}$ Briefly, the tests comprised: aesculin hydrolysis determined by inoculation of agar slants supplemented with aesculin $\left(1 \mathrm{gl}^{-1}\right)$ and ferric citrate $\left(0.5 \mathrm{gl}^{-1}\right)\left(30^{\circ} \mathrm{C}\right)$; Voges Proskauer reaction; acid production in arabinose and salicin peptone waters; gas production in glucose peptone water; gluconate oxidation; growth in the presence of potassium cyanide; and $\beta$ haemolysin production determined by inoculation of Columbia agar (Oxoid) plates containing 5\% sheep blood. All tests were incubated in air at $37^{\circ} \mathrm{C}$ (unless otherwise stated) for 18-24 hours.

\section{SUICIDE PHENOMENON}

The fermentation of glucose, with or without gas production and pelleting of bacteria (suicide phenomenon) was determined by inoculation of vessels containing nutrient broth (Oxoid) with $0.5 \% \mathrm{w} / \mathrm{v}$ glucose, $0.0015 \% \mathrm{w} / \mathrm{v}$ bromcresol purple, and inverted tubes. ${ }^{12}$ Tests were read after incubation at $30^{\circ} \mathrm{C}$ for $18-24$ hours. Additionally, for this method of speciation aesculin hydrolysis, as determined above, was also tested. $A$ hydrophila is non-suicidal,

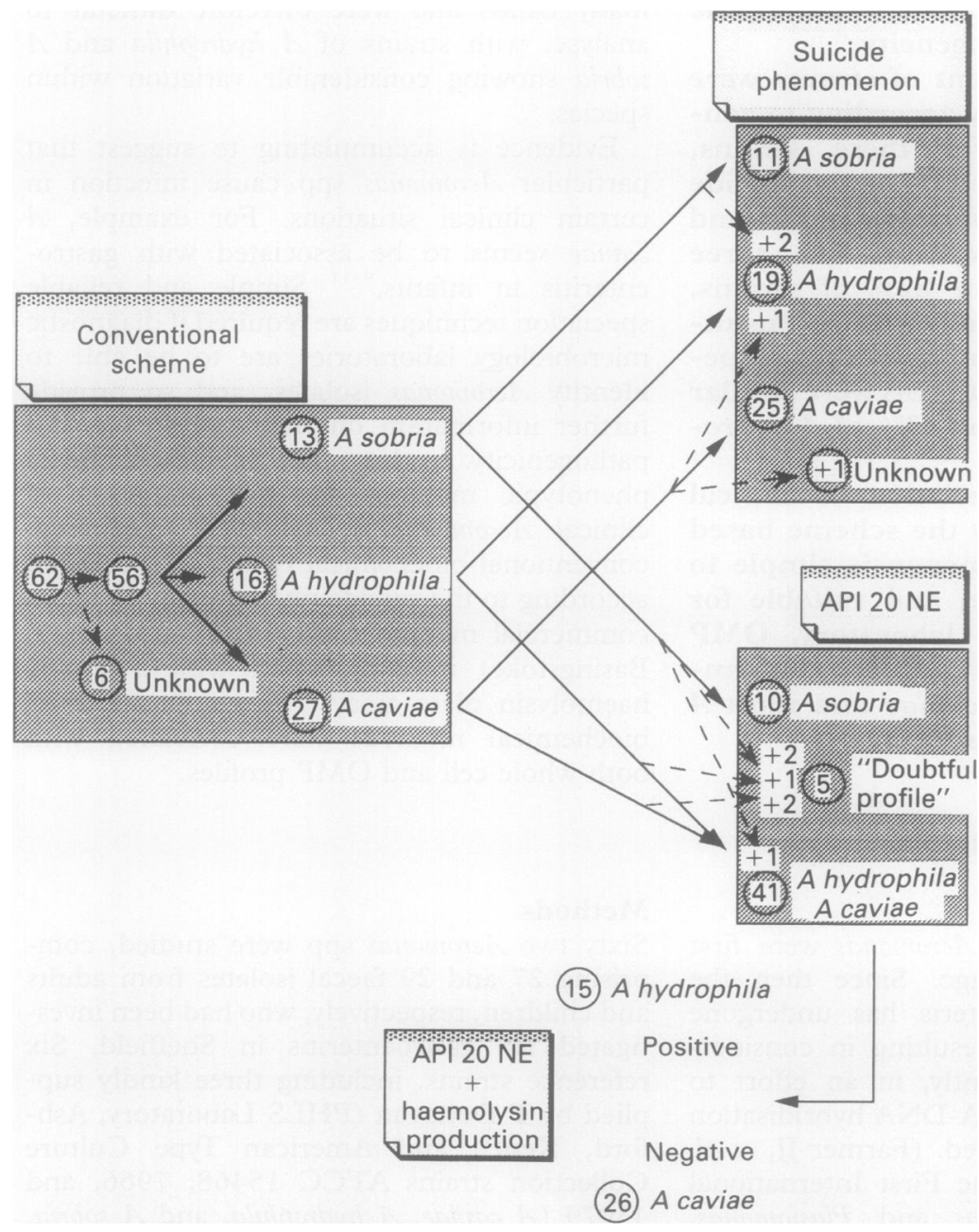

Figure 1 Phenotypic characterisation of aeromonads using three different methods of speciation. The figures inside circles represent the number of strains identified as a particular phenotype. The figures outside circles show the numbers of strains changing identity (dotted lines) from the conventional scheme results. Strains identified as either $A$ hydrophila or $A$ caviae by API $2 O N E$ were divided according to haemolysin production. aerogenic and aesculin positive; $A$ sobria is suicide variable, aerogenic and aesculin negative; $A$ caviae is suicidal, anaerogenic, and aesculin positive. ${ }^{12}$

API 20NE AND HAEMOLYSIN PRODUCTION

Identification strips were used according to the manufacturer's instructions and read after incubation at $30^{\circ} \mathrm{C}$ for 48 hours. As this method cannot be used to differentiate between $A$ hydrophila and $A$ caviae strains, haemolysin production (positive for $A$ hydrophila and negative for $A$ caviae) was also tested, as described above. ${ }^{713}$

SDS PAGE

Whole cell and OMP profiles were studied by sodium dodecyl sulphate polyacrylamide gel electrophoresis (SDS PAGE) ${ }^{14}$ Strains were cultured on a shaker in brain heart infusion broth (Oxoid) at $30^{\circ} \mathrm{C}$ for 18 hours, and were then centrifuged at $5000 \times g$ for 20 minutes. Whole cell protein samples were prepared by resuspending the bacteria in distilled water to an optical density of 0.5 at $590 \mathrm{~nm}$, and then centrifuging $10 \mathrm{ml}$ of this suspension at $5000 \times g$ for 20 minutes. Double strength sample buffer $(150 \mu \mathrm{l})$ (4 g SDS, $20 \mathrm{ml}$ glycerol, $10 \mathrm{ml} 2$-mercaptoethanol, $12.5 \mathrm{ml} 1 \mathrm{M}$ TRIS-buffer ( $\mathrm{pH} 6.8$ ), and $20 \mathrm{mg}$ bromophenol blue per $100 \mathrm{ml}$ distilled water) was added to the deposit. After boiling for five minutes $150 \mu \mathrm{l}$ of distilled water were added and boiling continued for a further five minutes. The supernatant fluid collected after centrifugation at $10000 \times g$ for 10 minutes represented the whole cell proteins.

OMPs were prepared by resuspending bacterial cells, cultured as above, in $5 \mathrm{ml} 50 \mathrm{mM}$ TRIS- $\mathrm{HCl}$ buffer (pH 7.4) to an optical density of 1.5 at $590 \mathrm{~nm}$. Suspended bacteria were lysed by sonication over ice for two one minute periods at $12 \mu \mathrm{m}$ peak-to-peak amplitude (MSE Scientific Instruments, Crawley, England). After centrifugation at $5000 \times g$ for 10 minutes to remove cell debris OMPs were separated from the supernatant fluid by adding $0.5 \mathrm{ml} \mathrm{20 \%} \mathrm{w/v} \mathrm{Sarkosyl} \mathrm{(Sigma,} \mathrm{Poole,} \mathrm{Eng-}$ land) and incubating at room temperature $\left(20^{\circ} \mathrm{C}\right)$ for 30 minutes. OMPs were collected by centrifugation at $50000 \times g$ for one hour at $4^{\circ} \mathrm{C}$, and then resuspended in $50 \mu 150 \mathrm{mM}$ TRIS- $\mathrm{HCl}$ buffer. Single strength sample buffer $(150 \mu \mathrm{l})$ was added, and then boiled as detailed for whole cell preparations.

Whole cell and OMPs were separated on $12 \%$ SDS PAGE gels (Mini Protean II Biorad, Hemel Hempstead, England), loading $10 \mu \mathrm{g}$ protein per lane. Molecular size standards (Sigma) were run concurrently. Following electrophoresis, gels were fixed and stained with Coomassie brilliant blue R250.

\section{Results}

The results of the three biochemical schemes for speciating Aeromonas spp are compared in fig 1 . Of 62 strains studied, six $(10 \%)$ gave inconclusive results according to the conventional scheme and are not included in the 
remaining analysis. Janda et $a l^{7}$ defined eight primary and nine supplementary phenotypic properties for identifying clinical isolates of Aeromonas spp. The six strains that could not be satisfactorily identified gave inappropriate results for at least two primary reactions. However, the six strains were morphologically similar to the remainder of Aeromonas isolates and satisfied the broad criteria detailed in the methods section. Fifty two out of 56 strains $(93 \%)$ gave the same species identification in the conventional and suicide phenomenon schemes; the corresponding figure for the API $20 \mathrm{NE}$ plus haemolysin assays was $49(88 \%)$ strains. The three schemes gave concordant results for $82 \%$ of strains tested. Four and two strains not identifiable by the conventional scheme were speciated as $A$ sobria by the API and suicide schemes, respectively. All 27 strains identified by the conventional scheme as $A$ caviae were haemolysin negative, while 15 out of $16 A$ hydrophila were haemolysin positive; seven ( $77 \%) A$ sobria were also haemolysin positive.

Gas production from the fermentation of glucose was frequently not detected using glucose peptone water. For 12 strains gas production was reproducibly negative in the latter method, but positive in the suicide tubes which contained nutrient broth and glucose, and these were incubated at $30^{\circ} \mathrm{C}$ instead of $37^{\circ} \mathrm{C}$. A separate experiment showed that the most critical factor was the temperature of incubation, gas production being more reliable at $30^{\circ} \mathrm{C}$ as opposed to $37^{\circ} \mathrm{C}$.

The whole cell protein profiles contained in excess of 40 bands which made comparison between species and strains difficult, and species specific patterns could not be identified with confidence (data not shown). The OMP profiles of 62 Aeromonas spp were grouped according to the identity of strains using the conventional biochemical scheme of speciation. For two of the three phenospecies, namely $A$ caviae (fig 2 ) and $A$ hydrophila (fig 3 ), striking similarities were noted between most isolates. A characteristic four band OMP profile was seen in 24 out of 27 (89\%) $A$ caviae, consisting of proteins with mean molecular weights (range) of 54 (51-60), 44 (40-48), 31 (27-35) and 29 (26-33) kilodaltons. A different, but again characteristic, four band protein profile was observed in 10 out of $16(63 \%) A$ hydrophila, consisting of 52 (50-55), 44 (42-64), $33(31-35)$ and $28(27-30)$ kilodalton proteins. As seen in $A$ caviae, the two high molecular weight OMPs were expressed more strongly than the remainder. Two isolates identified by conventional biochemical criteria as $A$ caviae had OMP profiles typical of $A$ hydrophila (tracks 3 and 4 from the right, fig 2). Both strains were haemolysin negative and identified as $A$ caviae by the API 20NE scheme, and in the suicide phenomenon one was characterised as $A$ caviae and the other "unknown". A sobria isolates had strongly heterogenous OMP profiles (fig 4), with one or two strongly expressed proteins within the high molecular weight ranges noted for the other two phenospecies. Of the six isolates not identified by conventional criteria, two had OMP profiles similar to the $A$ hydrophila pattern (tracks 1 and 2 from the left, fig 5), while the remainder were unrecognisable. Both of the former isolates were identified as $A$ hydrophila by the suicide phenomenon and API 20NE schemes.

\section{Discussion}

The large increase over the past decade in the number of publications on the genus Aeromonas has heralded the acceptance of several new genospecies and phenospecies. ${ }^{3}$ Similarly, studies now point to pathogenic roles for Aeromonas spp that were previously unrecognised. For example, we and others have provided evidence that $A$ caviae is implicated as a cause of gastroenteritis in children. ${ }^{9-11} A$ hydrophila and $A$ sobria can cause skin and soft

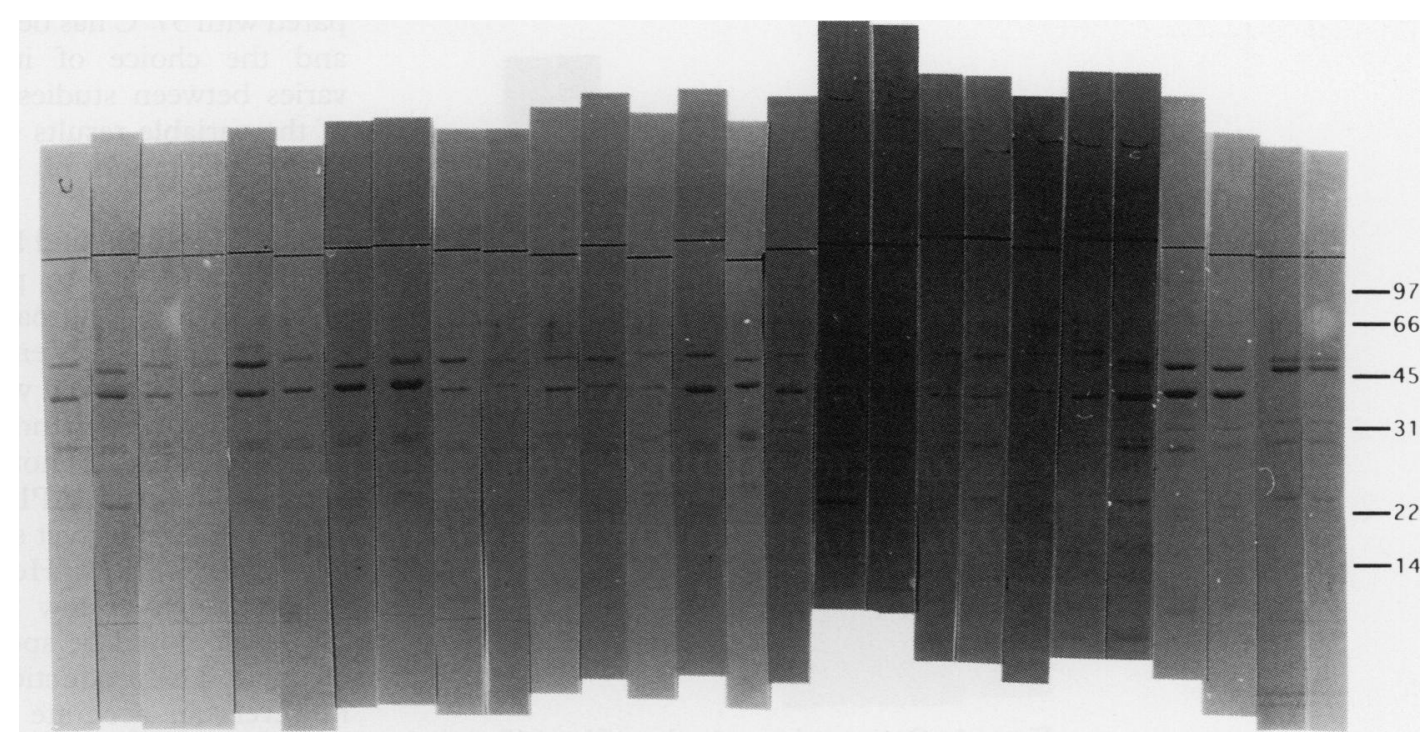

Figure 2 Outer membrane protein profiles of 27 strains identified as $A$ caviae by conventional criteria. A caviae type strain ATCC 15468 is in track 1 (from the left). Molecular weights are indicated at the far right side. 


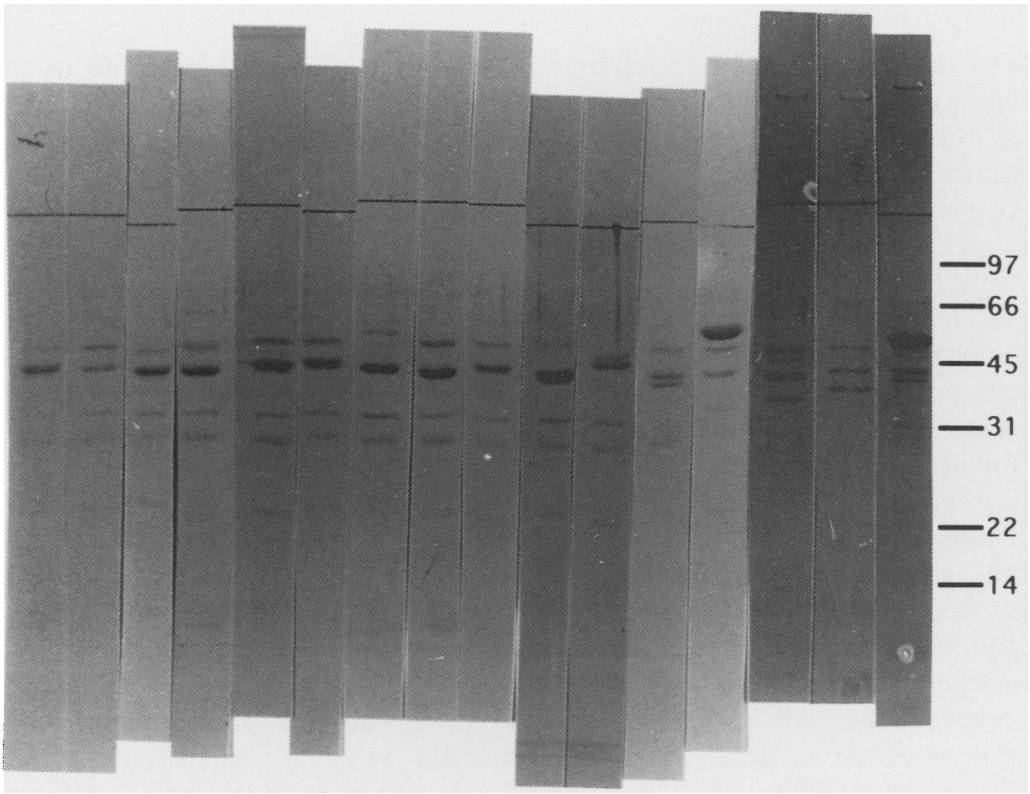

Figure 3 Outer membrane protein profiles of 16 strains identified as $A$ hydrophila by conventional criteria. A hydrophila type strain ATCC 7966 is in track 1 (from the left). Molecular weights are indicated at the far right side.

tissue infection and septicaemia in both immunocompromised and immunocompetent individuals. ${ }^{1}$ In vivo and in vitro studies indicate that the latter phenospecies are inherently more virulent that $A$ caviae. ${ }^{15-17}$ Unless diagnostic microbiology laboratories are encouraged to isolate and speciate these potential pathogens, further clarification of the behaviour of Aeromonas spp will be impeded.

Initial taxonomic studies based on 59 biochemical characteristics, of which seven were found to be of discriminatory value, described two mesophilic Aeromonas spp. ${ }^{6}$ Later modifications assigned clinical isolates to one of three phenospecies $A$ hydrophila, $A$ caviae, and $A$ sobria ${ }^{7}$; this terminology has been applied in this study. Several new phenospecies such as $A$ trota and $A$ jandaei have been proposed, but these are rarely recovered from clinical specimens. ${ }^{18} 19$ It is now appreciated that within

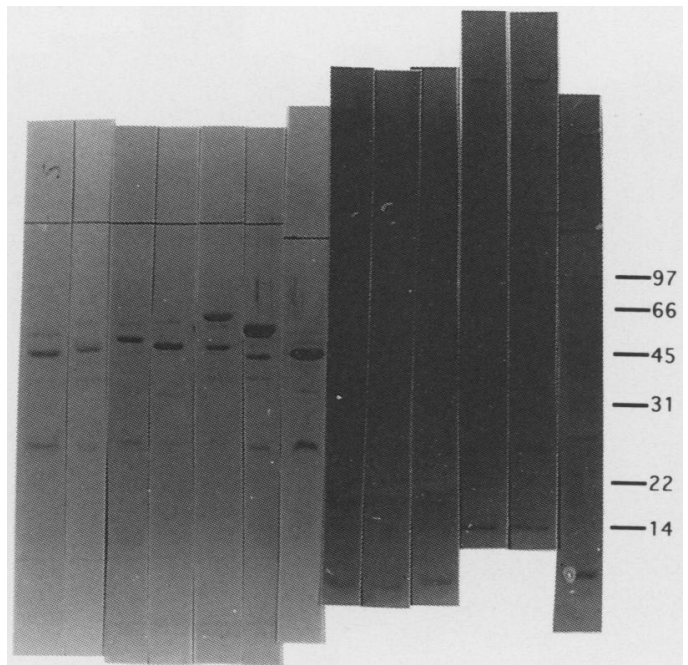

Figure 4 Outer membrane protein profiles of 13 strains identified as $A$ sobria by conventional criteria. $A$ sobria type strain ATCC 43979 is in track 1 (from the left). Molecular weights are indicated at the far right side.

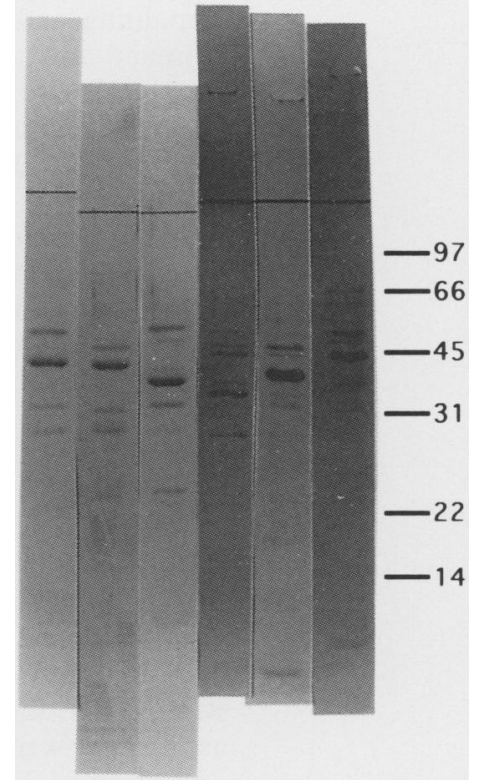

Figure 5 Outer membrane protein profiles of six strain not satisfactorily identified by conventional criteria. Molecular weights are indicated at the far right side.

each phenospecies more than one DNA hybridisation group exists. Nevertheless, most clinical isolates represent DNA groups 1, 4, and 8 , which correspond to the phenospecies outlined above. ${ }^{3}$

Three biochemical phenospeciation schemes have been compared which are amenable for use in the diagnostic laboratory. The gold standard results were taken as those obtained from the conventional scheme, although such assumptions may be flawed. This scheme is time consuming and laborious to perform, and does not easily lend itself to the occasional speciation of small numbers, because of problems with the limited shelf-life of media. When handling large numbers of strains it becomes most unwieldy. Furthermore, the reproducibility and subjectivity of tests such as growth in the presence of potassium cyanide (noted also in the present study) is apparent. ${ }^{20}$ The variable behaviour of Aeromonas spp at $30^{\circ} \mathrm{C}$ compared with $37^{\circ} \mathrm{C}$ has been described elsewhere, and the choice of incubation temperature varies between studies. ${ }^{2122}$ Our observations of the variable results of gas production from the fermentation of glucose confirm these findings.

The API 20NE and haemolysin assays were, by contrast, easy to perform. However, the results of this approach to speciation concurred with the conventional scheme for $\mathbf{8 8 \%}$ of isolates, compared with a figure of $93 \%$ for the suicide phenomenon scheme $(p>0 \cdot 1)$. It was interesting to note that the percentage acceptability of the API profile number bore no relation to the correct speciation of $A$ caviae/ $A$ hydrophila isolates. Hence a strain that had either a high or low probability of being $A$ hydrophila could be speciated as $A$ caviae, for example. The production of $\beta$ haemolysin was, however, an accurate discriminator between such isolates. The speciation scheme based on the presence or absence of the suicide phenomenon (the susceptibility of $A$ caviae and some $A$ 
sobria to acidic conditions) was accurate, simple, and inexpensive to perform. It requires only basic reagents and in total comprises only two tubes per strain tested. When describing this method of phenospeciation, Namdari and Bottone tested 210 clinical and environmental isolates and found that their results "paralleled" those achieved by conventional criteria. ${ }^{12}$ Whether strains that were only satisfactorily identified by the latter method were included in this analysis is unclear. A simplified key for speciating Aeromonas which can distinguish eight phenotypes using seven tests has recently been described. ${ }^{20}$ However, several of these species are rarely encountered clinically and the key incorporates antibiotic susceptibility testing using the Kirby-Bauer technique which is not favoured in Europe.

We were interested to compare the results of the above methods with the Aeromonas spp protein profile phenotypes to determine the intra-species homogeneity. Several studies have examined the protein profiles of Aeromonas spp, with widely differing patterns being obtained. ${ }^{82123-25}$ For example, the number of whole cell proteins clearly identified by SDS PAGE has varied from about six to $50 .^{2123-25}$ Our results agree with the higher figure and, particularly when using mini-gel apparatus, this makes the interpretation of profiles difficult. We were unable to identify species specific whole cell protein profiles. An earlier report observed about 20 Aeromonas OMPs, which gave somewhat "busy" protein profiles. ${ }^{8}$ Our extraction methods identified about four to six strongly expressed OMPs, and distinct patterns were noted for $89 \% A$ caviae and $63 \% A$ hydrophila, but not for $A$ sobria. Clearly, differing methods of protein extraction, including centrifugation speeds and cell lysis techniques, will influence the purity of OMP preparations, and hence, together with the sensitivity of detection methods, will determine the number of protein bands observed by SDS PAGE. Two unidentifiable isolates and two that were speciated as $A$ caviae by conventional criteria had OMP patterns typical of $A$ hydrophila, and the true identity of these Aeromonas spp remains uncertain.

We have not attempted to redefine or subdivide the phenospecies $A$ caviae, $A$ hydrophila, and $A$ sobria as this was not the aim of the study, and phenotypic criteria alone are insufficiently discriminatory for this purpose. We are presently investigating the potential of genotypic methods such as ribotyping for grouping Aeromonas spp, which may be able to clarify such problems. It seems clear that within the three phenospecies heterogenous strains exist, although this fact does not detract from the broad virulence properties ascribed to date to each group. ${ }^{3}$ OMP profiles are, however, a useful means of confirming the phenospeciation of $A$ caviae and some $A$ hydrophila isolates, as determined by simple biochemical schemes such as that based on the suicide phenomenon.
The latter technique is particularly suitable for use in the diagnostic microbiology laboratory.

1 Schubert RHW. Genus II Aeromonas, Kluyver and van Niel 1936. In: Buchanan R E, Gibbons N E, eds. Bergey's manual of determinative bacteriology. 8th edn. Baltimore: Wiliams and Wilkins Co, 1974:345-8.

2 Janda MJ, Duffey PS. Mesophilic aeromonads in human disease: current taxonomy, laboratory identification, and
infectious disease spectrum. Rev Infect Dis 1988;10: infectious

3 Janda MJ. Recent advances in the study of the taxonomy, pathogenicity and infectious syndromes associated with the genus Aeromonas. Clin Microbiol Rev 1991;4: 397-410.

4 Altwegg $M$, Steigerwalt AG, Altwegg-Bissig R, LuthyHottenstein J, Brenner DJ. Biochemical identification of Aeromonas genospecies isolated from humans. $\mathcal{F}$ Clin Microbiol 1990;28:258-64.

5 Popoff $M$, Lallier R. Biochemical and serological characteristics of Aeromonas. In: Bergan T, ed. Methods in istics of Aeromonas. In: Bergan T, ed. Methods in
microbiology. Vol 16. London: Academic Press, 1984; microbiolog.

6 Popoff $M$, Veron M. A taxonomic study of the Aeromonas hydrophila-Aeromonas punctata group. $\mathcal{f}$ Gen Microbiol 1976;94:11-22.

7 Janda MJ, Reitano M, Bottone EJ. Biotyping of Aeromonas isolates as a correlate to delineating a species-associated disease spectrum. F Clin Microbiol1 984;19:44-7.

8 Kuijper EJ, van Alphen L, Leenders E, Zanen HC. Typing of Aeromonas strains by DNA restriction endonuclease analysis and polyacrylamide gel electrophoresis of cell envelopes. $\mathcal{f}$ Clin Microbiol 1989;27:1280-5.

9 Namdari H, Bottone E J. Microbiologic and clinical evidence supporting the role of Aeromonas caviae as a paediatric pathogen. $\mathcal{f}$ Clin Microbiol 1990;28:827-40.

10 Pazzaglia G, Sack RB, Salazar E, et al. High frequency of coinfecting enteropathogens in Aeromonas-associated diarrhoea of hospitalised Peruvian infants. $\mathcal{f}$ Clin Microbiol 1991;29:1151-6.

11 Wilcox MH, Cook AM, Eley A, Spencer RC. Aeromonas spp. as a potential cause of diarrhoea in children. $f$ Clin Pathol 1992;45:959-63.

12 Namdari H, Bottone EJ. Suicide phenomenon in mesophilic aeromonads as a basis for species identification. $f$ Clin Microbiol 1989;27:788-9.

13 Kuijper EJ, Steigerwalt AG, Schoenmakers BSCIM, Peeters MF, Zanen HC, Brenner DJ. Phenotypic characterisation MF, Zanen HC, Brenner DJ. Phenotypic characterisation and DNA relatedness in human fecal isolat

14 Lugtenberg B, Meijers J, Peters R, Van der Hoek P, Van Alphen L. Electrophoretic resolution of the major outer membrane protein of Escherichia coli $\mathrm{K} 12$ into four bands. FEBS Lett 1975;58:254-8.

15 Janda JM, Clark RB, Brenden R. Virulence of Aeromonas species as assessed through mouse lethality studies. Curr Microbiol 1985;12:163-8.

16 Millership SE, Barer MR, Tabaqchali S. Toxin production by Aeromonas spp. from different sources. $\mathcal{F}$ Med Microbiol $1986 ; 22: 311-4$.

17 Watson IM, Robinson JO, Burke V, Gracey M. Invasiveness of Aeromonas spp. in relation to biotype, virulence factors, and clinical features. $f$ Clin Microbiol 1985;22: 48-51.

18 Carnahan A, Fanning GR, Joseph SW. Aeromonas jandaei (formerly genospecies DNA group 9 A. sobria), a new sucrose - negative species isolated from clinical specimens. F Clin Microbiol 1991;29:560-4.

19 Carnahan AM, Chakraborty T, Fanning GR et al. Aeromonas trota sp. nov., an ampicillin susceptible species isolated from clinical specimens. ₹ Clin Microbiol 1991; 29:1206-10.

20 Carnahan AM, Behram S, Joseph SW. Aerokey II: a flexible key for identifying clinical Aeromonas species. $f$ Clin Microbiol 1991;29:2843-9.

21 Statner B, Jones JM, George LW. Effect of incubation temperature on growth and soluble protein profiles of motile Aeromonas strains. F Clin Microbiol 1988;26: 392-3.

22 Kuijper EJ, Steigerwalt AG, Schoenmakers BSCIM, Peeters MF, Zanen HC, Brenner DJ. Phenotypic characterisation and DNA relatedness in human fecal isolates of Aeromonas spp. $f$ Clin Microbiol 1989;27:132-8.

23 Kokka RP, Vedros NA, Janda MJ. Electrophoretic analysis of the surface components of autoagglutinating surface array protein positive and surface array protein negative Aeromonas hydrophila and Aeromonas sobria. F Clin Microbiol 1990;28:2240-7.

24 Stephenson JR, Millership SE, Tabaqchali S. Typing of Aeromonas species by polyacrylamide gel electrophoresis Aeromonas species by polyacrylamide gel electrophoresis
of radiolabelled cell proteins. $f$ Med Microbiol 1987; 24:113-8.

25 Millership SE, Want SV. Typing of Aeromonas species by protein fingerprinting: comparison of radiolabelling and silver staining for visualising proteins. $\mathcal{f}$ Med Microbiol 1989;29:29-32. 